\title{
Isolation of Haemin-requiring Mutants of Escherichia coli K12
}

\author{
By MALCOLM L. MCCONVILLE* AND H. P. CHARLES \\ Department of Microbiology, The University, Reading $R G 15 A Q$
}

(Received 28 November 1978)

\begin{abstract}
Fifty-five haemin-requiring mutants were isolated from haemin-permeable mutants. According to their growth responses to haem precursors and their patterns of porphyrin accumulation, the 55 mutants fell into three groups which were judged to have defects in 5-aminolaevulinate dehydratase, ferrochelatase, and uroporphyrinogen III cosynthase or uroporphyrinogen decarboxylase. In mutants of the group deficient in 5-aminolaevulinate dehydratase, the mutations were adjacent to $l a c$, and evidence is presented that the mutations were in $h e m B$ and were commonly deletions extending into proC.
\end{abstract}

\section{INTRODUCTION}

Escherichia coli $\mathrm{K} 12$ is impermeable to haemin under normal cultural conditions (Săsărman et al., 1968), and genetic analysis of haem biosynthesis has depended on indirect methods. McConville \& Charles $(1975,1979 b)$ described mutants of E. coli K12 which are permeable to haemin. The present paper describes the isolation and study of haeminrequiring mutants derived from haemin-permeable mutants.

\section{METHODS}

Unless stated otherwise, the methods were those used by McConville \& Charles (1979a).

Media. Glucose minimal medium (GM) was medium E of Vogel \& Bonner (1956) supplemented with thiamin $\left(5 \mathrm{mg} \mathrm{1}^{-1}\right)$ and glucose $\left(5 \mathrm{~g} \mathrm{l}^{-1}\right)$. Glucose minimal agar (GMA) was GM containing Difco Bacto agar $\left(13 \mathrm{~g} \mathrm{l}^{-1}\right)$, autoclaved separately. When necessary, the glucose in GM was replaced by other sugars $\left(2 \mathrm{~g}^{-1}\right)$. Solutions of amino acids and other growth factors were sterilized by membrane filtration and aseptically added to minimal medium to give a final concentration of $40 \mathrm{mg} \mathrm{l}^{-1}$, except isoleucine and valine were added at 12 and $28 \mathrm{mgl}^{-1}$, respectively, and 5-aminolaevulinic acid (5-ALA) at $1 \mathrm{mg}^{-1}$. TNM contained $\left(\mathrm{g}^{-1}\right)$ : NaCl, 4; Difco Bacto nutrient broth, 8; $\mathrm{MgSO}_{4} \cdot 7 \mathrm{H}_{2} \mathrm{O}, 2 \cdot 47$. TNAM was TNM autoclaved with agar $\left(13 \mathrm{~g}^{-1}\right)$.

Stock solutions of haemin (type III, Sigma) and protoporphyrin IX (PP9; Calbiochem) were prepared by dissolving $0.2 \mathrm{~g}$ in $5 \mathrm{ml}$ Tween 80 and slowly diluting to $50 \mathrm{ml}$ with sterile distilled water; a few drops of alkali were added to give clear solutions. The procedure gave sterile solutions which were stored at $-18^{\circ} \mathrm{C}$ and added aseptically to give concentrations of $25 \mathrm{mg} \mathrm{1}^{-1}$ in TN media and $10 \mathrm{mg}^{-1}$ in GM media.

Genetical analysis. The transducing phage was P1kc; 12 min adsorption were allowed. Gene symbols and references to the E. coli linkage map follow Bachmann et al. (1976). Details of the strains are given in Table 1.

Assay of porphyrins accumulated in cultures. Bacteria were inoculated into two 21 flasks containing glucose minimal medium (400 ml) plus sodium thiosulphate $\left(10 \mathrm{mg}^{-1}\right)$ and 5-ALA $\left(50 \mathrm{mg}^{-1}\right)$; one flask contained haemin $\left(10 \mathrm{mg} \mathrm{l}^{-1}\right)$. Proline was added if required. Incubation was for $48 \mathrm{~h}$ at $37^{\circ} \mathrm{C}$ in an orbital incubator. Bacteria were then washed and resuspended in $10 \mathrm{ml}$ of glass-distilled water, and a $1 \mathrm{ml}$ sample was removed for drying and weighing. Porphyrins were extracted from the supernatant medium and bacteria by the method of Falk (1964). Coproporphyrin and protoporphyrin were extracted from the medium by adjusting to $\mathrm{pH} 4$ with glacial acetic acid and shaking with ethyl acetate. The aqueous phase was adjusted to $\mathrm{pH} 3 \cdot 2$ and uroporphyrin was extracted with ethyl acetate. Porphyrins in the ethyl acetate were then transferred to

* Present address: Inveresk Research International, Inveresk Gate, Edinburgh EH21 7UB. 
Table 1. Strains of Escherichia coli $\mathrm{K} 12$

Strain

AB1621

MLM106

MLM10613

MLM10629

MMK361

MMK376

SHSP3

AB2569

AB2575

AT2477

AT2508
Characteristics

$\mathrm{F}^{-}$ara lac $Y$ galK $x y l$ thiA mtl rpsL tsx $\lambda^{+}$

$\mathrm{F}^{-}$hemA106 mutant of AB1621

$\mathrm{F}^{-}$haemin-permeable mutant of MLM106; mutation incompletely mapped

$\mathrm{F}^{-}$haemin-permeable mutant of MLM106; mutation not mapped

$\mathrm{F}^{-}$hemB361 mutant of MLM10629 obtained by kanamycin selection

$\mathrm{F}^{-}$hemB376 proC mutant of MLM10629 obtained by kanamycin selection

$\mathrm{F}^{-}$thr ara leu tonA pro-36 lac $Y$ hemB3 purE gal trp arg $H$ malA $x y l$ mtl thi rps $L \lambda^{\mathrm{R}} \lambda^{-}$

$\mathrm{F}^{-} \lambda^{-}$proA2 lacY tsx galK his $x y l$ mtl argH thi met $A$

Hfr ilv

Hfr proB28 rel-1 metB1 $\lambda^{-}$

Hfr proC29 rel-1 metB1 $\lambda^{-}$
Reference/source

Adelberg et al. (1965)

McConville \& Charles

(1979b)

McConville \& Charles (1979b)

This paper

This paper

This paper

Săsărman \& Horodniceanu (1967): CGSC*

B. J. Bachmann

B. J. Bachmann

B. J. Bachmann

B. J. Bachmann

* CGSC, Coli Genetics Stock Center.

$3 \mathrm{M}-\mathrm{HCl}$ and treated as below. The bacteria were stirred with ethyl acetate/glacial acetic acid $(3: 1, \mathrm{v} / \mathrm{v})$ at $4{ }^{\circ} \mathrm{C}$ for $6 \mathrm{~h}$. Fragments were separated by centrifuging and extracted again, and the two supernatants were combined. The porphyrins were transferred to $3 \mathrm{M}-\mathrm{HCl}$ and separated, dried and esterified (Falk, 1964). The methyl esters were transferred to ether by extracting at $\mathrm{pH} 4$. The ether was removed and the mixtures of porphyrin methyl esters were dissolved in chloroform and separated by chromatography (Doss, 1969) on silica-gel plates using benzene/ethyl acetate/methanol (83:13.5:1.5, by vol.) as solvent. The amounts of esters present in the fluorescent spots were assayed by cutting out the spots, eluting the esters in chloroform $(2 \mathrm{ml})$, reading the absorbance at the Soret wavelength, and calculating the concentrations using the millimolar absorption coefficients quoted by Falk (1964).

Assay of 5-aminolaevulinate accumulated in culture medium. The modification by Gibson et al. (1958) of the method of Mauzerall \& Granick (1956) was used: $2 \mathrm{ml}$ sodium acetate/acetic acid buffer ( $\mathrm{pH} \mathrm{4.6,1} \mathrm{M}$ ), $0.05 \mathrm{ml}$ acetylacetone and $0.1 \mathrm{ml} \mathrm{NaOH}(2.5 \mathrm{M})$ were added to $2 \mathrm{ml}$ supernatant and the mixture was heated in a stoppered tube in boiling water for $10 \mathrm{~min}$. After cooling, an equal volume of modified Ehrlich's reagent was added, and $15 \mathrm{~min}$ later the absorbance was measured at $553 \mathrm{~nm}$ relative to a reference cuvette containing $2 \mathrm{ml}$ water and $2 \mathrm{ml}$ Ehrlich's reagent. Mauzerall \& Granick (1956) showed that $A_{553}$ at values up to $0 \cdot 8$ was linearly related to the 5-ALA concentration.

Extracts of bacteria. Extracts were prepared by treating suspensions for 10 periods of $30 \mathrm{~s}$ in an MSE $100 \mathrm{~W}$ ultrasonicator and then centrifuging to remove fragments and bacteria. Protein was estimated by the method of Lowry et al. (1951).

Assay of 5-aminolaevulinate dehydratase (EC 4.2.1.24), porphobilinogen deaminase (EC 4.3.1.8) and the ability to form porphyrins from porphobilinogen. The methods described by McConville \& Charles (1979a) were used. Porphobilinogen (PBG) was a gift from Dr G. Muller, Stuttgart University.

\section{RESULTS}

\section{Isolation of haemin-requiring mutants}

Strains MLM10613 and MLM10629 are haemin-permeable mutants of E. coli K12 (McConville \& Charles, 1979b). The gene(s) conferring haemin permeability have not been given symbols because they are incompletely mapped and defined. The permeable mutants carry allele hemA106 which confers a requirement for 5-ALA in normal K12 bacteria: in the permeable bacteria the requirement for 5-ALA is also satisfied by haemin. The hemA106 allele is present because it was necessary for the isolation of permeable mutants. From 
MLM10613 and MLM10629, mutants were isolated which required haemin and for which 5-ALA did not serve as a growth factor, the assumption being that each mutant would carry a second hem mutation, blocking a later reaction of haem biosynthesis. Two methods were used to obtain the mutants.

In one method, MLM10613 was treated with $N$-methyl- $N^{\prime}$-nitro- $N$-nitrosoguanidine, and then with penicillin and cycloserine (Ornston et al., 1969) in the presence of 5-ALA, to enrich for mutants having additional requirements. The suspension was then incubated for $14 \mathrm{~h}$ in GM containing haemin to allow the growth of haemin-dependent auxotrophs. Mutants which required haemin and did not respond to 5-ALA were detected by plating on GMA containing haemin and replicating on appropriate media after $48 \mathrm{~h}$. About $10^{4}$ colonies were replicated and 11 mutants were obtained. The mutants were given strain symbols of the form MMPC301 to MMPC335.

The second method made use of the fact that treatment of bacterial suspensions with low concentrations of aminoglycosides, such as streptomycin, neomycin and kanamycin, yields a high proportion of haem-deficient mutants amongst the survivors (Beljanski \& Beljanski, 1957; Săsărman et al., 1968; Tien \& White, 1968). It may be that the antibiotics select for respiratory mutants. The following procedure was used to detect haemin-dependent mutants. TNAM containing 5-ALA $\left(25 \mathrm{mg} \mathrm{l}^{-1}\right)$ was poured as $5 \mathrm{ml}$ volumes into 20 plates and allowed to set. Overlays $(7 \mathrm{ml})$ of similar medium containing MLM10629 (10 ${ }^{8}$ bacteria $\left.\mathrm{ml}^{-1}\right)$ and kanamycin $\left(50 \mathrm{mg} \mathrm{l}^{-1}\right)$ were then poured. After setting, overlays similar to the first layer were poured. The plates were held at $4{ }^{\circ} \mathrm{C}$ to allow the kanamycin to diffuse into the other layers and were then incubated for $48 \mathrm{~h}$. The positions of the 200 or so colonies which developed in each plate were then marked. Overlays $(7 \mathrm{ml})$ of TNAM containing haemin $\left(85 \mathrm{mg} \mathrm{l}^{-1}\right)$ were poured and allowed to set. All new colonies which developed after $72 \mathrm{~h}$ incubation were inoculated as patches on TNAM containing haemin and replica-plated to detect mutants which required haemin and for which 5-ALA was not a growth factor. From about 4000 colonies which developed in the seeded layers, 44 mutants were obtained. They were given symbols of the form MMK307 to MMK392.

\section{Nutritional evidence for four kinds of mutants}

The auxanographic method was used to test whether haem precursors satisfied the growth requirements of the mutants. The bacteria were seeded in GMA and TNAM. The parental bacteria in GMA were vigorously stimulated by 5-ALA, PBG, PP9 and haemin. The same substances gave weak stimulation in TNAM; haemin and PP9, but not PBG, gave better stimulation when dissolved in Tween $80(10 \%$, w/v) and applied as drops. The reason for the weak effect of PBG is not known; PBG is labile and its conversion to uroporphyrin may be accelerated in complex medium. In TNAM, 37 mutants (groups 1 and 2) responded to PBG, PP9 and haemin, 15 (group 3) to PP9 and haemin and 3 (group 4) to haemin only, consistent with defects in successively later reactions of haem biosynthesis. Mutants of groups 3 and 4 gave the same responses in GMA as in TNAM. Mutants of groups 1 and 2 behaved differently in GMA: 20 (group 1) responded only to PBG and 17 (group 2) did not respond to any of the test substances.

In a second round of auxanographic tests, representatives of groups 1 and 2 were seeded in GMA supplemented with haemin, and 150 potential growth factors were tested ( 3 per plate). Group 1 mutants required cysteine (or thiosulphate) plus haemin (or PP9) for growth. Group 2 mutants were not stimulated by cysteine and thiosulphate. In a third round of auxanography, with cysteine and haemin in the medium, group 2 mutants were found to require proline. Further tests showed that the group 2 mutants required proline plus cysteine plus haemin (or PP9).

Mutants of groups 3 and 4 responded to haemin in the absence of cysteine and thiosulphate; nevertheless, cysteine and thiosulphate stimulated their growth in the presence of haemin, but proline did not. 
Table 2. Accumulation of porphyrins by parental strains and mutants grown in GM containing 5-aminolaevulinate and haemin

Bacteria were grown for $48 \mathrm{~h}$ in GM containing 5-ALA (50 mg $\left.1^{-1}\right)$ and haemin $\left(10 \mathrm{mg} 1^{-1}\right)$; for the mutants, the medium was supplemented with sodium thiosulphate $\left(10 \mathrm{mg} 1^{-1}\right)$ and proline $\left(40 \mathrm{mg} 1^{-1}\right.$ ). Porphyrins were extracted separately from bacteria and supernatant medium, then esterified and separated as methyl esters on silica-gel plates. The esters were assayed by measuring the absorbance at the Soret wavelength and calculating the concentration using the millimolar absorption coefficients of Falk (1964). The results, expressed as nmol ( $\mathrm{g}$ dry wt bacteria) ${ }^{-1}$, indicate the total amounts of porphyrins accumulated, assayed as methyl esters. The results in parentheses indicate the amounts accumulated when haemin was not added to the medium. All mutants in each group were assayed and the average results are shown; the maximum and minimum quantities were within $10 \%$ for each group.

\section{Strain}

AB1621 (impermeable)

MLM106 (impermeable)

MLM10613 (permeable)

MLM10629 (permeable)

Mutants (20) of group 1

Mutants (17) of group 2

Mutants (15) of group 3

Mutants (3) of group 4

Uroporphyrin
$155(150)$
$145(136)$
$204(225)$
$163(196)$
0
0
540
145

Coproporphyrin
$252(317)$
$238(231)$
$305(332)$
$316(340)$
0
0
0
260

Protoporphyrin
$70(58)$
$43(46)$
$49(51)$
$64(56)$
0
0
0
420

The proline requirement is explained below. The probable reason for the cysteine requirement is referred to in the Discussion.

\section{Patterns of porphyrin accumulation: evidence for three kinds of mutants}

Doss \& Philipp-Dormston (1971) and Jacobs et al. (1972) showed that E. coli accumulated large amounts of uroporphyrin, coproporphyrin and protoporphyrin when grown with $0 \cdot 1 \mathrm{~mm}$-5-ALA. It therefore seemed likely that the mutants would show different patterns of porphyrin accumulation when grown in the presence of 5-ALA, depending on which enzyme was defective. The amounts of porphyrins accumulated are given in Table 2. Haemin did not block accumulation of porphyrins by parental bacteria grown in the presence of 5-ALA $\left(50 \mathrm{mg} \mathrm{l}^{-1}\right)$. The mutants accumulated only precursors proximal in biosynthesis to the earliest precursor which satisfied their individual requirement. Group 1 and 2 mutants did not accumulate porphyrins and behaved as if defective in 5-ALA dehydratase. Group 3 mutants accumulated only uroporphyrin, in agreement with the nutritional evidence that they did not convert PBG to PP9, and consistent with their having defects in uroporphyrinogen III cosynthase or decarboxylase. Mutants of group 4 accumulated uroporphyrin, coproporphyrin and protoporphyrin, in agreement with their nutritional dependence on haemin, and consistent with their having defects in ferrochelatase.

\section{Map location of a group 1 mutation}

In mapping the new hem mutations, account had to be taken of the fact that each strain carried the following three mutations: (i) mutation hemA106 at min 26, which caused a requirement for haemin; (ii) the incompletely mapped mutation(s) which caused the bacteria to be permeable to haemin; (iii) the individual mutation which caused each mutant to be dependent on haemin and unable to respond to 5-ALA. One resulting difficulty was that when the mutants were used as donors in gene-transfer experiments with normal impermeable K12 bacteria, the recombinants which received the new hem alleles were likely to be inviable or to grow very poorly because they could not use haemin supplied in the medium. 
A second difficulty was that when the new mutants served as recipients, and their individual hem mutations were replaced by the parental allele, the recombinants were still likely to score as hem mutants because they would retain the hem A106 mutation and the permeability mutation, and would respond to 5-ALA and haemin.

Because of the complications, and because the results were anomalous, the method of mapping a group 1 mutation will be described. In a time-of-transfer conjugation between donor AB2575 Hfr ilv and a permeable recipient MMK361 F- ara hem-361 galK rpsL, streptomycin $\left(200 \mathrm{mg} \mathrm{l}^{-1}\right)$ was added and isoleucine and valine were omitted from the plating media to select against the donor. Transconjugants which were $\mathrm{ara}^{+}, \mathrm{gal}^{+}$and hem-361+, respectively, were selected by plating on (i) arabinose minimal medium containing haemin, thiosulphate and streptomycin, (ii) galactose minimal medium containing haemin, thiosulphate and streptomycin and (iii) glucose minimal medium containing 5-ALA and streptomycin. Alleles $\mathrm{ara}^{+}$and $\mathrm{gal}^{+}$were transferred correctly after about 3 and $18 \mathrm{~min}$. Allele hem-361 $1^{+}$was transferred after about $13 \mathrm{~min}$, indicating a position near $\min 10$ on the linkage map.

Allele hem-36I was tested for cotransduction with genes in the min 10 region. Using the permeable donor MMK361 lacY hem-361 and recipient AT2508 proC29 metBl, selection was made for pro $C^{+}$transductants on GMA containing methionine. Because the recipient bacteria were impermeable, any pro $C^{+}$transductants which received allele hem-361 were expected to grow weakly, or not at all, even in the presence of haemin. After $48 \mathrm{~h}$ the transductant colonies were of two sizes, 1 and $5 \mathrm{~mm}$ in diameter. The large colonies were hem- $361^{+}$ and the small ones hem-361, as indicated by the following experiments. Fifty colonies of each size were restreaked on the same medium. Bacteria from large colonies gave colonies 5 to $6 \mathrm{~mm}$ in diameter and bacteria from small colonies gave colonies less than $0.5 \mathrm{~mm}$. Bacteria from small colonies were tested by auxanography in the presence of cysteine: they responded very weakly to PBG, PP9 and haemin. In liquid TNM, which contains glucose, they gave $5 \times 10^{8}$ bacteria $\mathrm{ml}^{-1}$ after $14 \mathrm{~h}$; when glucose or the complex organic supplements were omitted there was little growth. When bacteria from the liquid cultures were plated on TNAM supplemented with haemin, haemin-permeable derivatives arose spontaneously with a frequency of $10^{-7}$. Permeable derivatives of 10 transductants were tested by auxanography: they responded well to haemin plus cysteine, and to PBG alone, in the same way as mutant MMK361, but they also required methionine because of the met $B$ mutation.

Thus, in the transduction experiment, the small and large colonies were scored as hem-361 proC $^{+}$and hem- $361^{+}$proC $^{+}$, respectively. The results (Table 3 ) show $81 \%$ cotransduction of hem-361 with proC $C^{+}$. The closeness of proC to hem-361 indicated that lac should also be cotransducible with hem-361. Fortunately, the donor was lac $Y$ and the recipient was $l a c Y^{+}$. Fifty hem-361+ proC $^{+}$(large colony) transductants were tested for their ability to use lactose and all were $\mathrm{lac}^{+}$. Haemin-permeable derivatives of $50 \mathrm{hem}-361 \mathrm{proC}^{+}$transductants were isolated, and tested on lactose minimal medium supplemented with methionine, haemin and thiosulphate: all derivatives were $l a c$. It was surprising that the two genes hem-36I and lac $Y$ were always transduced together. The $81 \%$ cotransduction frequency for proC and lac was also anomalous: cotransduction frequencies for lac and proC of 8,20 and $20 \%$ were reported by Nakata et al. (1971), Markovitz (1964) and Broda (1974), respectively.

In the reciprocal transduction (Table 3), selection was made for hem-361+ transductants on GMA containing proline and 5-ALA. Tests for cotransduction with hem-361+ of proC and lac $\mathrm{Y}^{+}$were made by restreaking each hem-361+ transductant on glucose minimal medium (with 5-ALA), and on lactose minimal medium (with 5-ALA and proline). Genes hem-361+ and $\mathrm{lac}^{+}$showed $100 \%$ cotransduction. Genes hem- $361^{+}$and proC showed $89 \%$ cotransduction. The parent strain of the hem-361 mutant showed $13 \%$ and $18 \%$ cotransduction of lac $Y$ and proC in reciprocal transduction experiments with AT2508. The most likely explanation of the results is that the hem-361 mutation may have been a deletion which eliminated much of the DNA between the lac and proC regions, and which may have penetrated into 
Table 3. Cotransduction of hem-361 and hem-376 with proC and lac $Y$

\begin{tabular}{|c|c|c|c|c|c|c|}
\hline Donor & Recipient & $\begin{array}{c}\text { Selected } \\
\text { marker }\end{array}$ & $\begin{array}{c}\text { No. of } \\
\text { transduc- } \\
\text { tants scored }\end{array}$ & $\begin{array}{c}\text { No. of } \\
\text { transductan } \\
\text { carrying unsele } \\
\text { marker }\end{array}$ & $\begin{array}{l}\text { ts } \\
\text { ected }\end{array}$ & $\begin{array}{c}\text { Trans- } \\
\text { ductants } \\
\text { per } 10^{8} \\
\text { phage }\end{array}$ \\
\hline $\begin{array}{l}\text { MMK361 (permeable) } \\
\text { lacY hem-361 }\end{array}$ & AT2508 proC29 & pro $^{+}$ & 4415 & hem-361 lac $Y^{*} 3$ & 3585 & 170 \\
\hline AT2508 proC29 & MMK361 & hem $^{+}$ & 180 & $\begin{array}{l}\text { proC } \\
\text { lac }^{+}\end{array}$ & $\begin{array}{l}161 \\
180\end{array}$ & 8 \\
\hline AT2508 proC29 & $\begin{array}{l}\text { MMK376 (permeable) } \\
\text { lacY hem-376 pro }\end{array}$ & hem $^{+}$ & 635 & $\begin{array}{l}\text { pro }^{+} \\
\text {lac }^{+}\end{array}$ & $\begin{array}{r}0 \\
633\end{array}$ & 5 \\
\hline AT2477 proB28 & MMK376 & hem $^{+}$ & 529 & $\begin{array}{l}\mathrm{pro}^{+} \\
\mathrm{lac}^{+}\end{array}$ & $\begin{array}{l}529 \\
528\end{array}$ & 4 \\
\hline $\mathrm{AB} 2569$ proA2 & MMK376 & hem $^{+}$ & 550 & $\begin{array}{l}\text { pro }^{+} \\
\text {lac }^{+}\end{array}$ & $\begin{array}{l}550 \\
549\end{array}$ & 4 \\
\hline
\end{tabular}

* Because the recipient was impermeable to haemin, direct scoring of lac $Y$ amongst hem-361 proC transductants was not possible. Permeable derivatives of $50 \mathrm{hem}-361 \mathrm{proC}^{+}$transductants were isolated and tested: all were lac $Y$. All $h^{+} m^{+}$pro $C^{+}(50)$ tested were $l a c^{+}$.

lac. The mutant did not revert to hem ${ }^{+}$. Whether hem-361 or lac is nearer proC cannot be determined from the data.

\section{Evidence that mutation hem-361 may be in hemB}

Săsărman \& Horodniceanu (1967) described mutants which grew as small colonies on complex media; the mutations mapped in the lac region. Growth was not stimulated by haemin and 5-ALA, but the mutants were judged to be haem-deficient because they lacked cytochrome and catalase. The locus was designated $n c f$ by Săsărman \& Horodniceanu (1967) and hem by Săsărman et al. (1968). The locus was later referred to as hemB in the linkage map of $E$. coli (Taylor \& Trotter, 1972). Săsărman \& Horodniceanu (1967) stated that transduction experiments with phage Plkc confirmed close linkage between the $n c f$ and lac markers, cotransduction occuring at a high rate (99 to $100 \%$ in SHSP1, SHSP2 and SHSP3 recipients). When we tested strain SHSP3 by auxanography, its growth was not stimulated by 5-ALA, PBG, PP9 and haemin. Using the methods described above, the mutant was found to give haemin-permeable derivatives which responded to PBG, and to haemin and PP9 when cysteine or thiosulphate was present. The hem-361 mutation is therefore likely to be in $\operatorname{hem} B$, unless there is another gene in the region affecting the same part of haem biosynthesis.

\section{Nature of a group 2 mutation}

Mutants of group 2 required the same supplements as mutants of group 1, plus proline. Strain MMK376, carrying mutation hem-376, was used as recipient in transductions with pro $A, B$ and $C$ mutants as donors (Table 3 ). The transductions showed that the proline requirement was caused by a mutation in proC, at $\min 8 \cdot 7$, close to $l a c$ and hem $B$ at $\min 7 \cdot 9$. This suggested that group 2 mutations were hemB deletions which extended into proC. Because the mutations were induced in a lac $Y$ mutant it was not possible to determine from nutritional tests whether they extended into lac. They did not extend into proB at min 5.6. Two features of the data support the suggestion that group 2 mutants were deletions. Firstly, with proA and proB donors, $1079 \mathrm{hem}^{+}$transductants were all $\mathrm{pro}^{+}$. Secondly, the frequency of $\mathrm{hem}^{+}$transductants was low, consistent with many transducing fragments 
Table 4. Activities of 5-aminolaevulinate dehydratase and porphobilinogen deaminase

Bacteria were grown for $17 \mathrm{~h}$ in medium A, i.e. GM supplemented with 5-ALA, haemin, proline and sodium thiosulphate, or in medium GM supplemented as indicated. 5-ALA dehydratase activities are expressed as nmol PBG produced $\mathrm{h}^{-1}$ (mg protein $)^{-1}$, and PBG deaminase activities as nmol PBG consumed $\mathrm{h}^{-1}(\mathrm{mg} \text { protein })^{-1}$.

Growth medium A

$\overbrace{\begin{array}{c}5-A L A \\ \text { dehydratase }\end{array} \begin{array}{c}\text { PBG } \\ \text { deaminase }\end{array}}$

AB1621

MLM106 hemA

MLM10629 (permeable)

MMK361 hemB

MMK376 hemB proC

$\begin{array}{rr}8.9 & 4.4 \\ 11 \cdot 5 & 6 \cdot 6 \\ 9.2 & 4 \cdot 4 \\ 0.1 & 5 \cdot 3 \\ 0.1 & 4 \cdot 2\end{array}$

* Only substances necessary for vigorous growth were added.

Growth medium GM

\begin{tabular}{|c|c|c|}
\hline Supplement(s)* & $\begin{array}{c}\text { 5-ALA } \\
\text { dehydratase }\end{array}$ & $\begin{array}{c}\text { PBG } \\
\text { deaminase }\end{array}$ \\
\hline None & $8 \cdot 1$ & $6 \cdot 1$ \\
\hline 5-ALA & $9 \cdot 7$ & $5 \cdot 3$ \\
\hline $\begin{array}{l}\text { Haemin, } \\
\text { thiosulphate }\end{array}$ & $7 \cdot 9$ & $4 \cdot 2$ \\
\hline $\begin{array}{l}\text { Haemin, } \\
\text { thiosulphate }\end{array}$ & $0 \cdot 1$ & $4 \cdot 3$ \\
\hline Proline & $0 \cdot 1$ & $4 \cdot 5$ \\
\hline
\end{tabular}

carrying hem $B^{+}$failing to integrate because of lack of homology in the recipient. Only 4 of 1714 hem-376+ transductants were lac, showing almost $100 \%$ cotransduction of $\mathrm{lac}^{+}$with hem $B^{+}$but nevertheless suggesting that sufficient of the lac operon, distal to lac $Y$, was present in the deletion mutant to allow rare crossing-over.

\section{Enzyme deficiency of mutants MMK361 and MMK376}

The mutants MMK361 and MMK376 had characters consistent with defects in 5-ALA dehydratase. Crude extracts from parental and mutant bacteria grown in many different media were assayed for the dehydratase. The parental strains showed dehydratase activity and the mutants did not (Table 4). Haemin in the medium did not repress the enzyme in parental bacteria, whether permeable or impermeable.

The mutants were not deficient in PBG deaminase (Table 4). Ferrochelatase was not assayed. Other enzymes were not assayed separately, because pure substrates were not available, but extracts were tested for their ability to form porphyrins from PBG. Mutant and parental extracts all formed porphyrins, and to similar extents.

If the hem-361 and hem-376 mutations blocked 5-ALA utilization, they would be expected to cause 5-ALA to accumulate if they were transferred to $h e m A^{+}$bacteria which possess 5-ALA synthase. A hem-361 strain carrying hem $A^{+}$was obtained by cotransduction of hem-361 with pro $C^{+}$into AT2508 (Table 3). Because the strain was impermeable to haemin it grew as small colonies $(1.5 \mathrm{~mm})$ after $48 \mathrm{~h}$ on complete medium. A hem-361+ transductant, forming large colonies, served as control. The bacteria were grown in GM supplemented with (i) methionine, because they were metB1, (ii) sodium thiosulphate, because the mutant was expected to be deficient in sulphite reductase, and (iii) various concentrations of Casamino acids (Difco). Haddock \& Schairer (1973) found that a hemA mutant grew in a glucose mineral medium containing Casamino acids; Casamino acids were found to stimulate growth of the haem-requiring and haemin-impermeable hem-361 transductant. They may have stimulated growth by aiding fermentative metabolism; single amino acids were not stimulatory. Bacteria were incubated in $400 \mathrm{ml}$ volumes for $40 \mathrm{~h}$ and the supernatant medium was assayed for 5-ALA as described in Methods. The hem-36I+ strain did not accumulate detectable 5-ALA whereas the mutant accumulated up to $13.8 \mu \mathrm{mol}$ per $400 \mathrm{ml}$ supernatant. 


\section{DISCUSSION}

The use of permeable mutants removed the major difficulty in the way of genetical analysis of haem and porphyrin biosynthesis in E. coli. In addition, the kanamycin-selection method is efficient for isolating mutants, although it may be better for mutants blocked in 5-ALA dehydratase than for mutants blocked in later reactions. The patterns of nutritional requirement and precursor accumulation by mutants were consistent with each other, and pointed to the precise enzymic defects in mutants of groups 1, 2 and 4. In group 3, the defects may have been in either of two enzymes.

The efficiency of detection of mutants blocked in the conversion of PBG to haem may perhaps be increased by omitting cysteine and proline from the mutant isolation medium, or by supplying PBG, to eliminate the numerous mutants of groups 1 and 2 .

McConville \& Charles (1979b) found that the permeable strain MLM10613 gave inadequate titres of phage for transduction experiments. This was not a problem with derivatives of the permeable strain MLM10629, which were used in the present experiments.

A difficulty in genetical analysis was that when the $\operatorname{hem} B$ alleles were transferred to other K12 strains, the recombinants grew very weakly on minimal media because they were impermeable to haemin. It was found that when transferred to complex liquid media they grew sufficiently well to allow plating-out, and selection of permeable derivatives, when required. It is probable that anaerobic conditions occur in unshaken cultures in complex media. McConville \& Charles (1979b) observed that haemin-requiring mutants grew as well as their parental strains when incubated anaerobically without haemin.

In minimal medium, sulphur was supplied as sulphate. The hemB mutants obligatorily required sulphur in a more reduced form. They were probably deficient in sirohaem, the prosthetic group of sulphite reductase. Sirohaem is an iron-porphyrin having eight carboxyl groups (Murphy et al., 1973). It may arise by methylation of uroporphyrinogen III (Siegel et al., 1977), which has eight carboxyl groups, rather than from later precursors, which have fewer. The obligate requirement of hem $B$ mutants for reduced sulphur, in the presence of haemin or PP9, is evidence that haemin and PP9 are not converted to sirohaem by $\mathrm{K} 12$.

McConville \& Charles (1979 $b$ ) observed that haemin-permeable hem $A$ mutants, defective in 5-ALA synthase, grew well when supplied with haemin and sulphate, but better when supplied with haemin and cysteine or haemin and thiosulphate. This was also true of mutants of groups 3 and 4 in the present experiments. Thus, within the limits of the mutants available, mutants blocked immediately in PBG synthesis (5-ALA dehydratase) seemed to be fully defective in sirohaem synthesis, but mutants blocked earlier or later at most had a partial defect. Since PBG is a precursor of uroporphyrinogen III and hence of sirohaem and haem, mutants defective in 5-ALA dehydratase should lack both. They should obligatorily require cysteine when supplied with haemin but not when supplied with PBG; tests confirmed this was so. Mutants blocked after uroporphyrinogen III synthesis should be able to make sirohaem and should only require haemin. Two problems remain: firstly, why cysteine was stimulatory to mutants blocked in later reactions; and secondly, why hem $A$ mutants which required 5-ALA did not obligatorily require reduced sulphur when supplied with haemin instead. With respect to the second problem, mutants requiring 5-ALA are commonly leaky, and it is likely that they may be incompletely defective in 5-ALA synthesis. In that case, they may synthesize sufficient sirohaem to support growth when supplied with haemin. It is possible that mutants completely defective in 5-ALA synthesis are not isolated by the present methods.

The two hem $B$ mutants tested in the present experiments gave evidence of being deletion mutants. The proline requirement of 16 mutants of group 2 which were not studied genetically also points to their being deletion mutants. The evidence of Săsărman \& Horodniceanu (1967) again points to hemB mutants being deletions. Another possibility is that the mutations were inversions; however, there was a large difference in the frequency of 
transductants in the reciprocal transductions (Table 3), as would be expected in the case of deletion but not in the case of inversion. The deletions affecting proC may be more than 0.5 min of linkage map in length. A simple test for deletion would be to look for cotransduction of flanking markers which are normally a little too far apart for cotransduction.

It is not known why the lesions in all of the hem $B$ mutants are apparently deletions. Cook \& Lederberg (1962) observed that deletions in the lac region may be common. It is also possible that duplicate hem $B$ genes may exist in this region in which case the hem $B$ phenotype might only be expressed in deletion mutants.

The confirmation of a hemB locus at min 8 raises a problem with respect to a mutation studied by Powell (1975). Bacteria carrying sec-130 formed small colonies, accumulated 5ALA, and were deficient in 5-ALA dehydratase. The mutation was $27 \%$ cotransducible with ara at min 1 . It is therefore possible that group 1 mutations !may not all have been in the same gene. If Powell's observation were to be confirmed, a problem would arise as to the roles of the two genes in haem biosynthesis.

Acknowledgment is made to the Medical Research Council for a project grant to H. P. Charles, to David L. Morris for technical assistance, and to Dr Gerhard Muller for a generous gift of $\mathrm{PBG}$.

\section{REFERENCES}

Adelberg, E. A., Mandel, M. \& Chein Ching CHEN, G. (1965). Optimal conditions for mutagenesis by $N$-methyl- $N$-'nitro- $N$-nitrosoguanidine in Escherichia coli K12. Biochemical and Biophysical Research Communications 18, 788-795.

BachmanN, B. J., Low, K. B. \& Taylor, A. L. (1976). Recalibrated linkage map of Escherichia coli K12. Bacteriological Reviews 40, 116. 167.

Beljanski, M. \& Beljanski, M. (1957). Sur la formation d'enzymes respiratoires chez un mutant d'Escherichia coli streptomycine-resistant et auxotrophe pour l' hémine. Annales de l'Institut Pasteur 92, 396-412.

BrodA, P. (1974). Modified map positions for lac and the pro markers in Escherichia coli K12. Journal of Bacteriology 117, 741-746.

CoOK, A. \& Lederberg, J. (1962). Recombination studies of lactose non-fermenting mutants of Escherichia coli K12. Genetics 47, 1335-1339.

Doss, M. (1969). Separation, isolation and determination of proto-, copro-, pentacarboxy-, hexacarboxy-, heptacarboxy- and uroporphyrin. Hoppe-Seyler's Zeitschrift für physiologische. Chemie 350, 499-502.

Doss, M. \& Philipp-Dormston, W. K. (1971). Porphyrin and haem biosynthesis from endogenous and exogenous $\delta$-aminolaevulinic acid in Escherichia coli, Pseudomonas aeruginosa and Achromobacter metalcaligenes. Hoppe-Seyler's Zeitschrift für physiologische Chemie 352, 725-733.

FALK, J. E. (1964). Porphyrins and Metalloporphyrins. New York: American Elsevier

Gibson, K. D., Laver, W. G. \& Neuberger, A. (1958). Initial stages in the biosynthesis of porphyrins. Biochemical Journal 70, 71-81.

HadDock, B. A. \& SchaIreR, H. U. (1973). Electrontransport chains of $E$. coli. Reconstitution of respiration in a 5-aminolaevulinic acid-requiring mutant. European Journal of Biochemistry 35, 34-45.

JACOBS, N. J., JACOBS, J. M. \& MoRgan, H. (1972). Comparative effect of oxygen and nitrate on protoporphyrin and heme synthesis from $\delta$-aminolaevulinic acid in bacterial cultures. Journal of Bacteriology 112, 1444-1445.

Lowry, O. H., Rosebrough, N. J., Farr, A. L. \& RANDALL, R. J. (1951). Protein measurement with the Folin phenol reagent. Journal of Biological Chemistry 193, 265-275.

Markovitz, A. (1964). Regulatory mechanisms for synthesis of capsular polysaccharide in mucoid mutants of Escherichia coli $\mathrm{K} 12$. Proceedings of the National Academy of Sciences of the United States of America 51, 239-246.

Mauzerall, D. \& Granick, S. (1956). The occurrence and determination of $\delta$-aminolevulinic acid and porphobilinogen in urine. Journal of Biological Chemistry 219, 435-446.

McConville, M. L. \& Charles, H. P. (1975). Isolation of 'haemin-permeable' mutants and their use in the study of the genetics of haem biosynthesis in Escherichia coli K12. Proceedings of the Society for General Microbiology 3, 14-15.

McConville, M. L. \& Charles, H. P. (1979a). Mutants of Escherichia coli K12 accumulating porphobilinogen: a new locus, hemC. Journal of General Microbiology 111, 193-200.

McConville, M. L. \& Charles, H.P. (1979b). Mutants of Escherichia coli K12 permeable to haemin. Journal of General Microbiology 113, 165-168.

Murphy, M. J., Siegel, L. M., Kamin, H. \& Rosenthal, D. (1973). Reduced nicotinamide adenine dinucleotide phosphate-sulfite reductase of enterobacteria. II. Identification of a new class of haem prosthetic group: an iron tetrahydroporphyrin (isobacteriochlorin type) with eight carboxy- 
lic acid groups. Journal of Biological Chemistry 248 2801-2814.

Nakata, A., Peterson, G. R., Brooks, E. L. \& RothmaN, F. G. (1971). Location and orientation of the phoA locus on the Escherichia coli $\mathrm{K} 12$ linkage map. Journal of Bacteriology 107, 683-689.

Ornston, L. N., Ornston, M. K. \& Chou, G. (1969). Isolation of spontaneous mutant strains of Pseudomonas putida. Biochemical and Biophysical Research Communications 36, 179-184.

Powell, K. A. (1975). Studies on the genetics and biochemistry of haem synthesis in Escherichia coli. Ph.D. thesis, Reading University.

SǍSĂRMAN, A. \& HoRODNICEANU, T. (1967). Locus determining normal colony formation on the chromosome of Escherichia coli K12. Journal of Bacteriology 94, 1268-1269.

Săšrrman, A., Surdeanu, M., Szégli, G., Horodniceanu, T., Greceanu, V. \& Dumitrescu,
A. (1968). Hemin-deficient mutants of Escherichia coli K12. Journal of Bacteriology 96, 570-572.

Siegel, L. M., Davis, P. S. \& MurPhy, M. J. (1977). Incorporation of methionine-derived methyl groups into sirohaem by Escherichia coli. Biochemical Journal 167, 669-674.

TAYloR, A. L. \& TrotTer, C. D. (1972). Linkage map of Escherichia coli strain K12. Bacteriological Reviews 36, 504-524.

TIEN, W. \& WhITe, D. C. (1968). Linear sequential arrangement of genes for the biosynthetic pathway of protoheme in Staphylococcus aureus. Proceedings of the National Academy of Sciences of the United States of America 61, 1392-1398.

VoGel, H. J. \& BonNER, D. M. (1956). A convenient growth medium for Escherichia coli and some other micro-organisms (medium E). Microbial Genetics Bulletin 13, 43-44. 